\begin{tabular}{|c|c|c|}
\cline { 2 - 3 } & REVISTA SABERES APUDEP & Volumen 4 Número 1 \\
\hline
\end{tabular}

\title{
DESAFÍOS LINGÜÍSTICOS EN LA COMUNICACIÓN ORAL DESDE CONTEXTOS GLOBALES DE SIGNIFICADOS
}

\section{LINGUISTIC CHALLENGES IN ORAL COMMUNICATION FROM A GLOBAL PERSPECTIVES OF MEANINGS}

\section{Franklin Esteban Jaén}

Universidad de Panamá, Centro Regional Universitario de San Miguelito. Panamá. franklinjaen-12@hotmail.com https://orcid.org/0000-0001-8032-3405

\section{RESUMEN}

Analizar los desafíos de la lingüística en la comunicación oral desde una perspectiva global orientada a entender los actos del habla no como saberes declarativos, sino integrados en contextos comunicativos reales es el fundamento del presente artículo. Para ello, se considera el enfoque cualitativo bajo la investigación de tipo teórica documental, apoyada en un diseño bibliográfico de carácter analítico e interpretativo-crítico. Las técnicas e instrumentos de recolección de datos utilizados son la observación documental, el análisis de contenido y, una matriz de registro de las fuentes de información secundarias revisadas. Como consideraciones finales, se plantea que los desafíos se orienten en entender la concepción del lenguaje oral como práctica en la que la realidad discursiva se inscribe en diferentes contextos sociales y culturales; la aceptación del multilingüismo como rasgo para responder a la diversidad lingüística. Todo esto implica ampliar el desarrollo de las normas lingüísticas atendiendo a las convenciones pragmáticas y socioculturales involucradas en la labor de formar hablantes competentes, en contextos globales tecnologizados.

PALABRAS CLAVE: Desafío lingüístico, comunicación oral, lenguaje, globalización, tecnológica 


\begin{tabular}{c|c|c|}
\cline { 2 - 3 } & REVISTA SABERES APUDEP & Volumen 4 Número 1 \\
\hline
\end{tabular}

\begin{abstract}
Analyzing the challenges of linguistics in oral communication from a global perspective aimed at understanding speech acts not as declarative knowledge but integrated into real communicative contexts is the basis of this article. For this purpose, the qualitative approach is considered under the conception of a documentary theoretical research based on a bibliographic design, analytical and interpretive-critical. The data collection techniques and tools used are documentary observation, content analysis and a record matrix of revised secondary information sources. As final considerations it is proposed that the challenges are oriented in understanding the conception of oral language as a practice in which discursive reality is part of different social and cultural contexts; acceptance of multilingualism as a trait to respond to linguistic diversity. All this involves expanding the development of language standards by following the pragmatic and sociocultural conventions involved in the work of training competent speakers, in globalized and technological contexts.
\end{abstract}

KEYWORDS: Language challenge, oral communication, language, globalization, technology

\title{
INTRODUCCIÓN
}

La comunicación oral es un acto natural consustancial al ser humano y constitutivo de la persona como miembro de una especie. Cada vez que se utiliza, se hace uso del lenguaje y de signos lingüísticos en el mensaje, estos en su mayoría son arbitrarios y/o convencionales, ya que expresan lo que se transmite, y además lineales; ya que cada símbolo va uno detrás de otro. (Santiago Luces, 2015). 


\begin{tabular}{c|c|c|}
\cline { 2 - 3 } & REVISTA SABERES APUDEP & Volumen 4 Número 1 \\
\hline
\end{tabular}

Por consiguiente, se entiende que se genera un intercambio de ideas a través del habla, existiendo un código común que es la lengua, la que permite la transmisión y entendimiento del mensaje a través del canal definido. Para Mongada Ostios (2015) la comunicación oral:

Se revela como una actividad compleja en la que intervienen diversos tipos de entidades, representaciones y procesos. En ella, el emisor produce intencionalmente una expresión simbólica y la ofrece como indicio de su intención comunicativa. El destinatario, por su parte, ha de descodificar la expresión lingüística e inferir cuál es la relación entre el indicio ostensivo y la intención comunicativa del emisor para poder recuperar las representaciones que el emisor quería comunicar, acudiendo para ello a procesos heurísticos que tratan de buscar una explicación verosímil a partir de los datos disponibles.

Se interpreta la existencia de códigos en el que los mensajes llegan a través de los sentidos de manera temporal, apoyándose, en el caso oral, en signos lingüísticos y extralingüísticos. Con esto se afirma, que para comunicarse no es suficiente solo conocer la lengua, sino también es necesario la comprensión del sistema lingüístico para saber cómo servirse de ella en función del contexto social.

Por otra parte, dentro de la vinculación de la lingüística con la comunicación oral es reconocido que el conocimiento del aparato formal de la lengua oral y la enseñanza de los conceptos lingüísticos son aspectos que no tienen sentido en sí mismos si no se ponen al servicio, esto es lograr la comprensión y expresión del mensaje de forma adecuada, correcta, coherente y eficaz, a partir del enriquecimiento de las capacidades comunicativas, dominando además las destrezas de expresión y comprensión de mensajes orales que favorezcan una conducta expresiva adecuada en los diferentes escenarios de la comunicación humana (Mujica Salazar, 2015). 


\begin{tabular}{c|c|c|}
\cline { 2 - 3 } & REVISTA SABERES APUDEP & Volumen 4 Número 1 \\
\hline
\end{tabular}

En consecuencia, la lingüística en la enseñanza de la comunicación oral ha sido entendida en términos que el individuo logre alcanzar las capacidades expresivas y comprensivas, que le permitan producir enunciados adecuados a intenciones diversas de la comunicación oral en contextos heterogéneos.

Por otra parte, en relación a los contextos globales de significados en el marco de la comunicación oral Palacios Arias (2016) afirma que "no hay lenguaje sin contexto, pero se crea contexto con el lenguaje. El que habla, es un alguien y, como hablante habla a otro alguien sobre algo, en una situación determinada". De esto se entiende, que entre el lenguaje y el contexto existe una relación armónica, ambos se necesitan y se complementan; ya que, forman parte del sistema comunicacional.

Lo indicado anteriormente supone, que el proceso de interacción que realiza el individuo a través de la comunicación oral entra en acción, conjuntamente, con sus conocimientos lingüísticos, habilidades para comprender y construir significados en correspondencia con los contextos sociales y culturales donde se lleva a cabo esta. Por ello, Mongada Ostios, (2015), señala que el acto de comunicación, supone "tener en cuenta la intención comunicativa del emisor y el objeto del mensaje lingüístico para que el receptor pueda descifrarlo en función del código que dispone y, así el contexto comunicativo oral cumpla su propósito lingüístico, situacional o sociocultural".

En consecuencia, esto permite identificar que existe diversidad lingüística, por lo que el lenguaje debe apropiarse, adecuarse y adaptarse en cada contexto comunicativo para ser entendible por el receptor. De esta manera, su implicación va más allá de ser la conjunción de procesos de codificación y descodificación, sino que requiere que cada uno de sus elementos incidan de manera definitiva en el transmitir algo, 


\begin{tabular}{c|c|c|}
\cline { 2 - 3 } & REVISTA SABERES APUDEP & Volumen 4 Número 1 \\
\hline
\end{tabular}

transformando los entornos físicos y cognoscitivos del interlocutor, en tanto que el oyente construye representaciones similares a las de quien emite.

Lo anterior permite entender que el contexto comunicativo oral, la lengua y, por consiguiente, la lingüística sufren cambios de manera gradual. Así frente a los modelos tradicionales como la conversación cara a cara o telefónica, en la actualidad se asiste a transformaciones en los intercambios comunicativos, en los modos de establecer relaciones sociales, revolución favorecida también, en algunos casos, por el avance tecnológico. Así, el chat, junto a la videoconferencia, los mensajes grabados en los móviles, entre otros, propician y condicionan el surgimiento de nuevos marcos y espacios de interacción social oral comunicativa y lingüística en el umbral del siglo XXI. (Arnoux, 2015)

Es así como, dentro de esta cosmovisión, la aparición de comunidades discursivas globales caracterizadas por una marcada diversidad idiomática, así como por los diferentes medios de transferencias de los mensajes y, la ubicación del emisor y receptor, han generado fronteras lingüísticas, en algunos casos resultando menos claras, propiciando modificaciones en determinados comportamientos lingüísticos, como cambio de códigos, diálogos poliglósicos y de comunicación oral asimétrica en los que coinciden distintas lenguas en el mismo episodio lingüístico, constituyéndose en un rasgo esencial de los entornos comunicativos orales, que se rigen por la eficacia instrumental de las lenguas $y$, asumen con naturalidad las competencias parciales de los interlocutores. 


\begin{tabular}{c|c|c|}
\cline { 2 - 3 } & REVISTA SABERES APUDEP & Volumen 4 Número 1 \\
\hline
\end{tabular}

En consecuencia, se entiende que la lingüística como disciplina del lenguaje a tenido que evolucionar y adecuarse a las dinámicas cambiantes de los diferentes escenarios y contextos en el que se expresa la comunicación oral; a partir de este planteamiento, surge el interés y propósito de este estudio en analizar los desafíos lingüísticos de la comunicación oral desde una perspectiva global orientada a entender los actos del habla, no como saberes declarativos, sino integrados en contextos comunicativos reales.

\section{MATERIALES Y MÉTODO}

Con referencia al aspecto metodológico, en esta disertación se utiliza el paradigma cualitativo para sustentarlo, el tipo de investigación documental de acuerdo a lo referido por Martínez Guevara (2015), que la define como "una estrategia de comprensión y análisis de realidades teóricas mediante la revisión, cotejo o comprensión de distintos tipos de fuentes documentales referentes a un tema, a través de un abordaje sistemático y organizado". De allí que el diseño es bibliográfico, en virtud que se ocupa de la revisión de fuentes físicas, tales como libros publicados, textos impresos, electrónicos, entre otros.

Dentro de las etapas concretas del proceso de investigación documental, una vez seleccionada y recopilada la información, a través del método de análisis hermenéutico indicado por Nieto Alargó, (2015) se procede a la sistematización e integración de los datos extraídos de las fuentes secundarias de información, para posteriormente, triangularla y generar la correspondiente organización del producto de investigación documental. Por otra parte, como técnica e instrumento de 


\begin{tabular}{c|c|c|}
\cline { 2 - 3 } & REVISTA SABERES APUDEP & Volumen 4 Número 1 \\
\hline
\end{tabular}

recolección de datos, la observación y análisis de contenido y una matriz para registrar las fuentes de información de carácter secundario.

Con respecto a la fuente de obtención de los datos, la búsqueda bibliográfica se realizó durante los meses de noviembre de 2019 a marzo de 2020. Para obtener todos los datos e información de este estudio, se realizaron varias búsquedas accediendo a través de internet, a la literatura científica recogida en los diferentes recursos. Asimismo, se emplearon buscadores como el Google y el Google Académico, utilizando los tesauros de biblioteconomía y documentación, publicado por el Consejo Superior de Investigaciones Científicas sobre la base de los términos definidos en el Centro de Información y Documentación Científica (CIN-DOC). De igual manera, se consultaron libros, revistas científicas en físico.

\section{RESULTADO}

Como resultado de los diecinueve (19) documentos consultados para determinar el estado teórico que permitiera dar respuesta al propósito del estudio, estos se clasificaron en una secuencia cronológica, configurándose la matriz de análisis con cuatro (4) categorías:

Categoría 1. La interacción lingüística en la comunicación oral:

De las referencias consultadas, se logró en el análisis concretizar que:

Que el estudio de la comunicación oral implica, desde ópticas de diferentes teóricos, tener en cuenta no solo los elementos lingüísticos, sino también los supra lingüísticos y paralingüísticos, relacionados conjuntamente, con el objetivo de la comunicación y de la intención del hablante al expresarse; todo ello, para no solo dar cuenta de lo que -110 - 


\begin{tabular}{c|c|c|}
\cline { 2 - 3 } & REVISTA SABERES APUDEP & Volumen 4 Número 1 \\
\hline
\end{tabular}

se dice, sino trascender y determinar lo que quiere decir $y$, el efecto que causa en los interlocutores. Así, el mensaje es comprendido en la medida en que el oyente comparte una serie de representaciones sociales que le permiten acceder al contexto y, al conjunto de supuestos lingüísticos que maneja al momento de la interacción oral. (Barrios Cuevas, 2016)

En la competencia lingüística, la utilización del lenguaje es entendido como instrumento de representación, interpretación y comprensión de la realidad, de construcción y transmisión del conocimiento en la organización y autorregulación del pensamiento, las emociones y la conducta; de igual manera, la sociolingüística, referida a la habilidad de adecuación al contexto comunicativo, es decir, el uso apropiado de la lengua oral en diferentes escenarios sociales. (Carvajal López, 2015) Categoría 2. Configuración del contexto global:

De las seis referencias consultadas, se logró en el análisis enfatizar que:

El contexto global de significados que sirven de soporte a la comunicación oral subyace en entender los escenarios desde donde se subscribe el proceso, llámese social o humano y; en el que la lingüística debe adecuar su esencia. Los desafíos se orientan en entender la concepción del lenguaje oral como práctica en la que la realidad discursiva se inscribe en diferentes contextos sociales y culturales; la aceptación del multilingüismo como rasgo para responder a la diversidad lingüística. Todo esto implica ampliar el desarrollo de las normas lingüísticas atendiendo a las convenciones pragmáticas y socioculturales involucradas en la labor de formar hablantes competentes, en contextos globales y tecnologizados. (Corrado Atanacio, 2017) 


\begin{tabular}{c|c|c|}
\cline { 2 - 3 } & REVISTA SABERES APUDEP & Volumen 4 Número 1 \\
\hline
\end{tabular}

La comunicación oral se concibe en un contexto definido por parámetros extralingüísticos que condicionan de manera inmediata la actividad discursiva identificándose como: Situación de producción: Incluye los elementos del enunciador, el destinatario y el objetivo del discurso para dar referencia a un contexto discursivo. Situación de recepción: Es el espacio propio en que el discurso es procesado por el destinatario, tomando en consideración los elementos propios del receptor con los que decide interpretar el mensaje. Se refiere a esta como contexto de uso o situación. Situación de interacción: Representada como la zona de cooperación donde se produce la comunicación social, en la que cada uno adopta cierto rol definido por el tipo de conectividad en la que participa. (Ferrari, 2016)

Se entiende que, como parte global de significados de contextos en el marco de la comunicación oral, se enuncia un escenario estrictamente lingüístico vinculado al acto del habla que interactúa con las funciones sociales y culturales y, otro extralingüístico enmarcado por las circunstancias geográficas, sociales, culturales, entre otros que rodean al discurso oral. (Miranda Solis, 2017)

Categoría 3. Avances lingüísticos en la comunicación oral

Se han generado adelantos que corresponden a la vinculación dentro de la comunicación oral con los contextos lingüísticos y no lingüísticas. (Mujica Santos, 2017)

La lingüística debe avanzar progresivamente hacia el logro de una comunicación oral pluricultural y plurilingüe, fundamentada en las nuevas formas de entender los contextos comunicativos, como por ejemplo la tecnología, haciendo posible el desarrollo de las destrezas básicas para saber ser y convivir, aprender a conocer la densidad de conceptos, la multiplicidad de contextos, la diversificación de ámbitos, la 


\begin{tabular}{c|c|c|}
\cline { 2 - 3 } & REVISTA SABERES APUDEP & Volumen 4 Número 1 \\
\hline
\end{tabular}

facilidad en el acceso a los mismos, y la proliferación de instrumentos comunicativos propios de la sociedad actual. (Pereira Castro, 2015)

Otro aspecto relevante en la lingüística comunicativa oral es la apertura a las explicaciones del significado de manera más integradora. El cambio se ha manifestado en un movimiento que va desde una lingüística unidireccional, focalizada en el habla de una persona, hacia la bidireccional en la que la explicación de los significados y las estructuras toma en cuenta la colaboración de por lo menos dos en una interacción contextual. (Riascos Diaz, 2015)

Como avance de la lingüística desde el campo interdisciplinario, el hecho de apoyarse en áreas como la psicolingüística, sociolingüística, entre otros, por lo que la comunicación oral deja de ser un sistema aislado para convertirse en un instrumento de interacción de experiencias del hombre como ser social y cultural. (Ruíz Fuentes, 2015)

La adquisición de un multienfoque en la lingüística le ha dado complejidad y variabilidad a la comunicación humana. (Sanabria Torres, 2015)

\section{Categoría 4. Desafíos y retos lingüísticos en la comunicación oral.}

Se encuentra aún por superar la monotonía y repetición mecánica lingüística presentes en el discurso oral, las cuales siguen siendo amenazas. Por lo cual es una tarea compleja el intentar de manera ulterior, no solo concienciar a los hispanohablantes sobre las iterativas incorrecciones lingüísticas en que se cae, sino también seducirlos en relación con los beneficios que el arte del bien hablar proporciona. (Terrado Cárdenas, 2015) 


\begin{tabular}{c|c|c|}
\cline { 2 - 3 } & REVISTA SABERES APUDEP & Volumen 4 Número 1 \\
\hline
\end{tabular}

Se enfatiza el arraigo en la comunicación oral de un discurso con prevalencia de vicios de dicción lingüística que genera el empleo de vocablos inadecuados, tales como: El hiato, entendido como el sonido desagradable que proviene del encuentro de las mismas vocales (generalmente tónicas), pertenecientes a palabras contiguas (vocal final con vocal inicial, respectivamente). Ejemplo: La agua por el agua; Los vulgarismos, definidos como la construcción innecesaria de las palabras o alteración de su sentido semántico. Ejemplos: ¿Quién lo indujo al crimen? por ¿Quién lo indujo al crimen?; La cacofonía, se indica como el sonido desagradable que se produce por el encuentro o repetición de las mismas sílabas dentro de una oración. Ejemplos: Tómate un té y te aliviarás; La redundancia, pleonasmo vicioso que consiste en emplear vocablos innecesarios, que solo repiten ideas ya expresadas. Ejemplo: Es necesario limpiar con el limpiador de ropa. Estas situaciones, condicionan la comunicación oral, por lo que aún es un desafío superar la pobreza léxica. (D’Sousa Carmet, 2015)

Constituye, por otra parte, un imperativo académico que los profesionales de todas las áreas del saber, aparte de gozar del conocimiento específico, refuercen y ostenten también el poder de la palabra, lo cual permite compartir los saberes de una manera más eficaz y efectiva. $\mathrm{Y}$ en el contexto lingüístico de la comunicación oral hacerla pertinente y de amplitud de acción. El desafío será atender cada vez más los modos de participación en las brechas educativas, considerando el proceso de globalización y la expansión de las nuevas tecnologías de la información y la comunicación, dentro del campo de la lingüística y la oralidad. (Bolívar Acosta, 2017)

- Desde otra línea del pensamiento, se indica que otro gran reto que se presenta en la lingüística y su vinculación con la comunicación oral deriva del doble compromiso 


\begin{tabular}{c|c|c|}
\cline { 2 - 3 } & REVISTA SABERES APUDEP & Volumen 4 Número 1 \\
\hline
\end{tabular}

con los avances de esta disciplina y, con los cambios de la sociedad. Por un lado, es fundamental adaptarse a las tecnologías y entrar de manera decidida a la transdisciplinariedad y; por otro, es necesario articular la teoría con la práctica para mejorar la explicación de los significados en la dinámica social. La tecnología ofrece la posibilidad de analizar grandes cantidades de datos y de avanzar en la comprensión de las lenguas y las culturas, pero queda el reto de lo que se puede hacer con estos grandes corpus. El desafío sigue siendo la confrontación de paradigmas, desde un debate epistemológico que hay que enfrentar de manera directa para describir la oralidad en contextos dinámicos y vinculantes con la interacción social. (Malavé Enriquez)

La lingüística debe conocer el discurso oral humano como creador de realidades y vehículo de significados sociales e ideológicos, para considerar su valor en la convivencia social. Para ello, el mayor desafío es redefinir su objetivo, método y objeto, ya que, como consecuencia de los enfoques interdisciplinarios, a menudo, se pierde de vista qué es lo netamente lingüístico. Es necesario responder extendiendo y profundizando los conocimientos básicos aplicados sobre el lenguaje oral, poniendo empeño en contribuir con su instrumentarium a resolver problemáticas actuales de orden sociocultural y de interés general. Seguidamente, sobre esto, favorecer y mejorar la adquisición, generación, distribución y almacenamiento de conocimientos relevantes por parte de la ciudadanía, bajo las nuevas formas de la comunicación oral globalizada. (Ponte Villareal, 2016)

Es interesante destacar el pasaje del multilingüismo al pluriculturalismo. El primero es el conocimiento de varias lenguas o la coexistencia de distintas lenguas en una sociedad determinada sin que haya una conexión entre ellas, esas lenguas no 


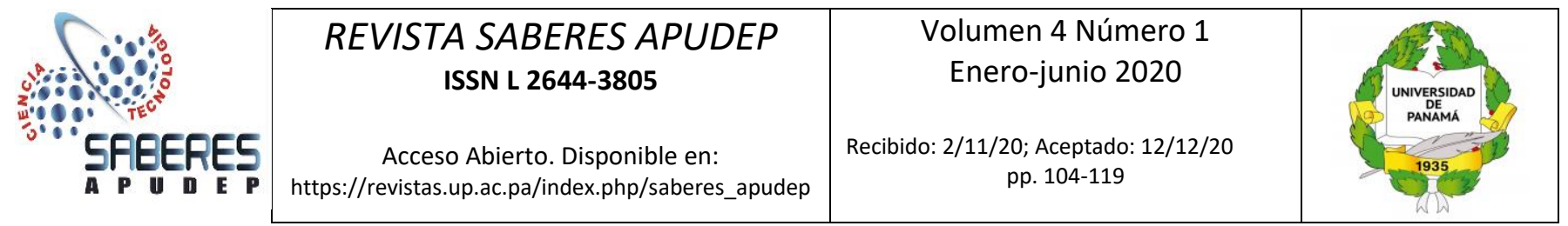

desarrollan la competencia comunicativa oral del hablante, por lo que las competencias de una lengua no son transferibles a otra, es decir, el hablante no aprovecha los logros de una lengua nativa para compensar el fallo en otra. Por el contrario, el usuario recurre a la que domina al presentársele la situación de bloqueo lingüístico. El desafío se orienta en lograr la competencia plurilingüe, es decir, la interrelación de los conocimientos y experiencias que se posee en diversas lenguas y culturas. El objetivo es sumar lo lingüístico a lo cultural para desarrollar la competencia comunicativa oral evitando el choque cultural, desarrollándose conocimiento y una tolerancia hacia ellas.

\section{CONCLUSIÓN}

En función de los resultados y del objetivo planteado, se precisa entender inicialmente como mayor desafío de la lingüística, el no considerar el lenguaje como único y verdadero objeto de la comunicación oral, sino entenderlo integrado en contextos reales; en el cual no solo se requiere descodificar el mensaje que el emisor transmite, sino trascender lo dicho e inferir lo que este quiere decir, basado en los elementos supra lingüísticos y paralingüísticos, así como en el conocimiento del interlocutor y el entorno.

Por consiguiente, la comunicación oral, a través del lenguaje, se transforma en un modo de actividad estableciendo la dicotomía acto/acción. En la cual la acción lingüística hace del lenguaje un medio para la consecución de determinados fines y, el acto lingüístico, como tal, es el modo de significar y dar sentido al mensaje. 


\begin{tabular}{c|c|c|}
\cline { 2 - 3 } & REVISTA SABERES APUDEP & Volumen 4 Número 1 \\
\hline
\end{tabular}

Dentro de los desafíos lingüísticos en la comunicación oral desde contextos globales de significados se devela que:

La lingüística debe dejar de ser solo un factor normativo descriptor de la lengua para permitir desde lo inter y multidisciplinario el posicionamiento de la comunicación oral como elemento central de interacción humana y social.

Se ha generado adelantos frente a los modelos tradicionales de comunicación oral favorecida por el avance tecnológico, entre otros contextos, propiciando y condicionando el surgimiento de nuevos marcos y espacios de interacción lingüística en el umbral de la actual sociedad, por lo cual los retos se proyectan en superar la monotonía y repetición mecánica lingüística presentes en el discurso oral. Resulta fundamental adaptarse a las nuevas tecnologías y entrar a la transdisciplinariedad, articulando la teoría con la práctica para mejorar la explicación de los significados en la dinámica social.

En síntesis, dentro de las diferentes posturas sobre los desafíos de la lingüística en el escenario de la comunicación oral revisadas, se entiende que los caminos que ha tomado esta son diversos y, en cada uno de ellos el reto se plantea de manera diferente. Sin embargo, desde una perspectiva general, el mayor de ellos, en esta época de ciencia despersonalizada y despersonalizante, está en erigirse como una disciplina que realmente coadyuve al individuo en el proceso comunicativo oral individual y social. Para ello, requiere una amplitud de miras aceptando lo que podría denominarse incorrecciones lingüísticas como realidades diversas y concretas de la cotidianidad. 


\begin{tabular}{|c|c|c|}
\cline { 2 - 3 } & REVISTA SABERES APUDEP & Volumen 4 Número 1 \\
\hline
\end{tabular}

\section{REFERENCIAS BIBLIOGRÁFICAS}

Arnoux, E. (2015). La lingüística y la oralidad: Aportes fundamentales. Tesis, Universidad de Buenos Aires, Argentina.

Barrios Cuevas, T. (2016). El lenguaje y la comunicación en el siglo XXI. Caracas, Venezuela: UPEL-IMPM.

Bolívar Acosta, A. (2017). Una aproximación teórica a la lingüística comunicacional en la postmodernidad. Tesis, Universidad Central de Venezuela, Lingüística, Caracas. Venezuela.

Carvajal López, A. (2015). Lengua y oralidad en internet. Barcelona, España: Ariel Prácticum.

Corrado Atanacio, J. (2017). ¿Cómo entender la comunicación lingüística desde la transcomplejidad? Tesis, Universidad Autónoma de México, Lingüística, México D.F.

D'Sousa Carmet, D. (2015). El lenguaje oral: características del español usado en Internet. Sao Paulo, Brasil: Editora Hucitec.

Ferrari, S. (2016). La riqueza del multienfoque de la lingüística en la lengua oral. Tesis, Universidad de Los Andes, Humanidades y Letras, Mérida. Venezuela.

Malavé Enríquez, C. (s.f.). La oralidad y la informática. México: Siglo XXI Editores.

Martínez Guevara, M. (2015). Métodos de investigación. Bogotá, Colombia: Co-Bo.

Miranda Solís, C. (2017). La Transcomplejidad lingüística comunicacional. Tesis, Pontificia Universidad Católica de Valparaíso, Chile.

Mongada Ostios, B. (2015). La conciencia de la estructura lingüística. Madrid, España: E-educativa.

Mujica Salazar, B. (2015). Aprendizaje del lenguaje oral. Barcelona: Anthropos. 


\begin{tabular}{|c|c|c|}
\cline { 2 - 3 } & REVISTA SABERES APUDEP & Volumen 4 Número 1 \\
\hline
\end{tabular}

Mujica Santos, C. (2017). El modelo contextual interaccionista y las estrategias metalingüísticas en el cibertexto. Aneca.

Nieto Alargón, M. (2015). Metodología de la Investigación. Bogotá. Colombia: Ediciones de la U. P.

Palacios Arias, S. (2016). Comunicación, lenguaje y contexto. Barranquilla, Colombia: Ayuso.

Pereira Castro, T. (2015). Entender la lingüística y sus aportes en tiempos de complejidad. Tesis, Universidad Autónoma de México, Lingüística, México D.F

Ponte Villareal, T. (2016). El discurso oral digital. Tesis Doctoral, Universidad Central de Venezuela, Facultad de Linguística, Caracas. Venezuela.

Riascos Diaz, E. (2015). Lenguaje oral. Madrid, España: Cambridge.

Ruíz Fuentes, A. (2015). La linguística y el discurso oral: Un análisis sustancial. Tesis, Universidad Del Zulia, Humanidades, Saladillo. Zulia.

Samarria Torres, C. (2015). Nuevos conocimientos, conceptos y prácticas de la cultura comunicativa oral. Tesis Maestría, Universidad del Valle, Calí, Colombia.

Santiago Luces, M. (2015). La lingüística del lenguaje. Estudios en torno a los procesos de significar y comunicar. Tesis Maestría, Universidad Pedagógica Nacional, Lingüística, Bogotá. Colombia.

Terrado Cárdenas, L. (2015). La oralidad: Creación y cambios culturales. Cartagena, Colombia: Fondo de Cultura. 